\title{
Parasitismo em ovos de percevejos da soja Euschistus heros (Fabricius) e Piezodorus guildinii (Westwood) (Hemiptera: Pentatomidae) em São Gabriel do Oeste, MS $^{1}$
}

\author{
Parasitism on eggs of stinkbugs Euschistus heros (Fabricius) and Piezodorus guildinii (Westwood) \\ (Hemiptera: Pentatomidae) in São Gabriel do Oeste (Mato Grosso do Sul State, Brazil).
}

\author{
Karlla Barbosa Godoy ${ }^{1}$ Júlio César Galli² Crébio José Ávila²
}

\begin{abstract}
Este trabalho foi realizado nas safras 2000/2001 e 2001/2002 e teve como objetivo avaliar o parasitismo em ovos dos percevejos Euschistus heros e Piezodorus guildinii na Região de São Gabriel do Oeste, MS, Brasil. Coletaram-se massas de ovos dos percevejos durante o período reprodutivo da soja em áreas em que não havia sido efetuada aplicação de inseticidas químicos. No laboratório, as massas de ovos foram individualizadas em placa de Petri contendo algodão umedecido em água e mantidas à temperatura ambiente até a completa emergência do parasitóide elou eclosão de ninfas dos percevejos. Após a morte dos parasitóides, determinou-se a porcentagem de parasitismo em cada época de coleta. As posturas de $\boldsymbol{E}$. heros e $\boldsymbol{P}$. guildinii coletadas em 2001 apresentaram, em média, 62,5\% e 23,8\% de parasitismo nos ovos, respectivamente. Em, $2002 \boldsymbol{E}$. heros e P. guildinii apresentaram em média 59,3\% e 39,5\% de parasitismo, respectivamente. A espécie predominante de parasitóide encontrada, em ovos de $\boldsymbol{E}$. heros e de $\boldsymbol{P}$. guildinii foi Telenomus podisi.
\end{abstract}

Palavras-chave: percevejo fitófago, controle biológico, Telenomus podisi.

\section{ABSTRACT}

This work was carried out in the soybean growing seasons of 2000/2001 and 2001/2002 with the aim of evaluating the egg parasitism of stinkbugs Euschistus heros and Piezodorus guildinii at São Gabriel do Oeste region in the State of Mato Grosso do Sul, Brazil. Stinkbugs egg masses were collected in areas not sprayed with chemical insecticides during the soybean reproductive stage. In the laboratory, the egg masses were individualized in Petri dishes with a wet cotton wick and kept at room temperature until the complete emergence of the parasitoid and/or stinkbug nymph. After parasitoid death, the parasitism per egg mass and the parasitism index were determined for each collecting period. The $\boldsymbol{E}$. heros and $\boldsymbol{P}$. guildinii egg masses collected in 2001 growing season showed an average of $62.5 \%$ and $23.8 \%$ parasitism, respectively. In 2002 growing season, the average parasitism of $59.3 \%$ and $39.5 \%$ for $\boldsymbol{E}$. heros and $\boldsymbol{P}$. guildinii, respectively. The main parasitoid species found in both $\boldsymbol{E}$. heros and $\boldsymbol{P}$. guildinii eggs was Telenomus podisi.

Key words: phytophagous stinkbug, biological control, Telenomus podisi.

Várias espécies de percevejos da família Pentatomidae são pragas da cultura da soja no Brasil, sendo Nezara viridula (Linnaeus), Piezodorus guildinii (Westwood) e Euschistus heros (Fabricius) as mais abundantes, causando sérios prejuízos, tanto no rendimento como na qualidade do produto colhido (PANIZZI \& SLANSKY Jr., 1985; CORRÊAFERREIRA, 1993).

Dos inimigos naturais de percevejos, os parasitóides de ovos têm sido constatados em vários países, sendo, em muitos casos, considerados os mais importantes agentes de mortalidade natural dessas pragas (JONES JUNIOR, 1979). Dentre os parasitóides de ovos de pentatomídeos fitófagos destacam-se os microhimenópteros Trissolcus basalis

Parte da tese apresentada à Universidade Estadual Paulista (UNESP), Faculdade de Ciências Agrárias e Veterinárias (FCAV) para obtenção do título de Doutor em Entomologia Agrícola.

${ }^{2}$ Engenheiro. Agrônomo, Doutor, Empresa Brasileira de Pesquisa Agropecuária (EMBRAPA) - Agropecuária Oeste, CP 661, 79804-970, Dourados, MS. E-mail: karlla@cpao.embrapa.br, avila@cpao.embrapa.br

${ }^{3}$ Engenheiro Agrônomo, Doutor, UNESP, FCAV, Paulo Donatto Castellane s/n, 14884-900, Jaboticabal, SP. E-mail: jcgalli@ fcav.unesp.br 
(Wollaston) e Telenomus podisi (Ahsmead) (PANIZZI \& SLANSKY Jr., 1985), sendo o primeiro, o principal inimigo natural de $N$. viridula em seu estágio de ovo (MOREIRA \& BECKER, 1987). A primeira citação da ocorrência de $\boldsymbol{T}$. basalis em ovos de $\boldsymbol{N}$. viridula no Brasil, foi feita por CORRÊA-FERREIRA (1980), na região norte do Paraná. Na região de Dourados, MS, GODOY \& ÁVILA (2000) observaram que T. podisi foi a principal espécie de parasitóide encontrada em ovos de $\boldsymbol{E}$. heros e de $\boldsymbol{P}$. guildinii.

O objetivo deste trabalho foi identificar os parasitóides que ocorrem em ovos dos percevejos $\boldsymbol{P}$. guildinii e $\boldsymbol{E}$. heros e avaliar a porcentagem de parasitismo, na região de São Gabriel do Oeste, MS.

A pesquisa foi conduzida em lavouras de soja e também utilizando o laboratório do Horto Florestal da Secretaria de Meio Ambiente (SEMA) de MS. Os levantamentos de parasitóides foram realizados no período reprodutivo da soja, coletandose posturas dos percevejos, nas safras 2000/2001 e 2001/2002. Estas coletas foram realizadas em dez áreas diferentes, de aproximadamente 1 ha, que não receberam aplicações de inseticidas químicos. Apenas nas áreas 1, 5 e 6 , foram realizadas coletas de postura nos dois anos, pois as demais não houve plantio ou ocorrência de percevejo.

As posturas coletadas foram individualizadas em placas de Petri contendo um chumaço de algodão umedecido em água e mantidas à temperatura ambiente. Para cada postura, foram registradas a data de coleta, a espécie de percevejo e o número de ovos. As posturas foram observadas diariamente, até a completa eclosão das ninfas dos percevejos e/ou emergência dos parasitóides, determinando-se a porcentagem de parasitismo. Os parasitóides emergidos dos ovos de cada espécie de percevejo hospedeiro foram conservados em álcool $70 \%$ e, posteriormente, encaminhados a especialistas para identificação. As densidades populacionais dos percevejos foram determinadas através do método do pano de batida (EMBRAPA, 2000).

Na safra 2000/2001, foram coletadas 1270 posturas de $\boldsymbol{E}$. heros e 30 de $\boldsymbol{P}$. guildinii (Tabela 1), evidenciando-se que o percevejo marrom foi predominante na região de São Gabriel do Oeste, MS. Os ovos de $\boldsymbol{E}$. heros apresentaram alta porcentagem de parasitismo, variando de $39,1 \%$ a $94,1 \%$. Entretanto, na espécie $\boldsymbol{P}$. guildinii o parasitismo foi menor variando de $0 \%$ a $35 \%$. Telenomus podisi foi a espécie de parasitóide predominante em ovos de $\boldsymbol{E}$. heros (98\%) e de P. guildinii (100\%). Verificou-se que $2 \%$ dos ovos de $\boldsymbol{E}$. heros estavam parasitados por uma espécie não identificada de Neorileya (Chalcidoidea: Euritimidae). YEARGAN (1979) também verificou que $\boldsymbol{T}$. podisi foi o parasitóide que predominou em quatro espécies de percevejos coletados em soja e alfafa nos EUA.

A porcentagem de parasitismo para $\boldsymbol{E}$. heros foi maior nas áreas $3(94,1 \%)$ e $5(87,9 \%)$. A área 3 provavelmente teve alta porcentagem de parasitismo (Tabela 2), devido há 4 anos, praticamente nenhum inseticida químico ter sido aplicado na cultura da soja, tanto para o controle de lagartas como para percevejo. As áreas 1, 2 e 6 apresentaram relativamente menor porcentagem de parasitismo em ovos de $\boldsymbol{E}$. heros, provavelmente porque nessas áreas ocorre tradicionalmente maior número de aplicações de inseticidas químicos.

Em 2002, foi coletado maior número de posturas de E. heros (1396) e de P. guildinii (151) em relação à safra anterior. Da mesma forma, a porcentagem de parasitismo também foi superior para $\boldsymbol{E}$. heros em relação à $\boldsymbol{P}$. guildinii para as

Tabela 1 - Total de posturas e de ovos avaliados em cada área de coleta, porcentagem de parasitismo dos ovos e espécies de parasitóides observados em $\boldsymbol{E}$. heros e $\boldsymbol{P}$. guildinii, na safra 2000/2001. São Gabriel do Oeste, MS.

\begin{tabular}{|c|c|c|c|c|c|}
\hline Local & Hospedeiro & Posturas & $\mathrm{N}^{\mathrm{o}}$ de Ovos & Parasitismo (\%) & Parasitóide \\
\hline \multirow[t]{2}{*}{ ÁREA 1} & E. heros & 235 & 842 & 55,7 & $\begin{array}{c}\text { Telenomus podisi }(95 \%) \\
\text { Neorileya } \text { sp. }(5 \%)\end{array}$ \\
\hline & P. guildinii & 3 & 61 & 0 & - \\
\hline ÁREA 2 & E. heros & 384 & 2198 & 44,9 & $\begin{array}{c}\text { T. podisi }(95 \%) \\
\text { Neorileya } \operatorname{sp~}(5 \%)\end{array}$ \\
\hline \multirow[t]{2}{*}{ ÁREA 3} & E. heros & 344 & 1400 & 94,1 & $\begin{array}{c}\text { T. podisi }(99 \%) \\
\text { Neorileya } \mathbf{s p}(1 \%)\end{array}$ \\
\hline & P. guildinii & 7 & 198 & 35,0 & T. podisi $(100 \%)$ \\
\hline \multirow[t]{2}{*}{ ÁREA 4} & E. heros & 190 & 1178 & 68,2 & T.podisi $(100 \%)$ \\
\hline & P. guildinii & 20 & 411 & 24,1 & T.podisi $(100 \%)$ \\
\hline ÁREA 5 & E. heros & 34 & 141 & 87,9 & T.podisi $(100 \%)$ \\
\hline ÁREA 6 & E. heros & 83 & 442 & 39,1 & T. podisi $(100 \%)$ \\
\hline \multirow[t]{2}{*}{ Total } & E. heros & 1270 & 6201 & 62,5 & $\begin{array}{c}\text { T. podisi }(98 \%) \\
\text { Neorileya } \text { sp }(2 \%)\end{array}$ \\
\hline & P. guildinii & 30 & 670 & 23,8 & T. podisi $(100 \%)$ \\
\hline
\end{tabular}

Ciência Rural, v.35, n.2, mar-abr, 2005. 
Tabela 2 - Número de coletas de ovos de percevejos e número médio de adultos $(\mathrm{A})$ e ninfas $(\mathrm{N})$ de percevejos por batida de pano, em cada área de coleta. São Gabriel do Oeste, MS.

\begin{tabular}{lccc}
\hline Áreas (A) & $\begin{array}{c}\mathrm{N}^{\mathrm{o}} \text { de } \\
\text { coletas }\end{array}$ & $\begin{array}{c}\mathrm{N}^{\mathrm{o}} \text { médio de } \\
\text { adultos }(\mathrm{A})^{1}\end{array}$ & $\begin{array}{c}\mathrm{N}^{\circ} \text { médio de ninfas } \\
(\mathrm{N})^{1}\end{array}$ \\
\hline A1 ** & $4 / 4$ & $0,7 / 1,5$ & $0,6 / 4,2$ \\
$\mathrm{~A} 2 *$ & 5 & 0,4 & 1,2 \\
$\mathrm{~A} 3 *$ & 3 & 0,6 & 0,6 \\
$\mathrm{~A} 4 *$ & 4 & 0,5 & 0,1 \\
A5 ** & $2 / 4$ & $0,5 / 0,2$ & $0,4 / 0,5$ \\
A6 ** & $2 / 3$ & $0,5 / 0,0$ & $0,6 / 0,3$ \\
A7 *** & 4 & 1,1 & 3,6 \\
A8 *** & 4 & 2,1 & 5,1 \\
A9 *** & 2 & 0,7 & 2,8 \\
A10*** & 2 & 16,5 & 20,3 \\
\hline
\end{tabular}

${ }^{1}$ Número médio de percevejos, observados por pano de batida em cada área na ocasião da coleta.

* Área utilizada para coletas em 2001; ** Área utilizada para coleta em 2001e 2002; ***Área utilizada para coleta em 2002. diferentes áreas de levantamento. Das posturas de E. heros coletadas, as maiores porcentagens de parasitismo foram verificadas nas áreas $1(84,7 \%)$, $10(81,1 \%), 9(76,3 \%)$ e $8(75,5 \%)$ e menor parasitismo na área $6(6,1 \%)$. Nas áreas $1,7,8$ e 10 foram observadas posturas de $\boldsymbol{P}$. guildinii (Tabela 3). A semeadura na área 10 foi bastante tardia, não sendo aplicados nenhum inseticida químico e a população de percevejo foi elevada, apresentando, em média, 16,5 adultos e 20,3 ninfas por pano de batida (Tabela 2).

Em 2001, a área 1 teve uma menor percentagem de parasitismo $(55,7 \%)$ que em 2002 $(84,7 \%)$. O inverso ocorreu com as áreas 5 e 6, que apresentaram menores porcentagens de parasitismo de ovos em 2002 (Tabelas 1 e 3). O aumento da porcentagem de parasitismo na área 1 , provavelmente, se deve ao fato de que nesta área vem sendo adotado o manejo integrado, principalmente com uso de produtos menos agressivos aos parasi-

Tabela 3 - Total de posturas e de ovos avaliados em cada área de coleta, porcentagem de parasitismo dos ovos e espécies de parasitóides observados em $\boldsymbol{E}$. heros e P. guildinii, na safra 2001/2002. São Gabriel do Oeste, MS.

\begin{tabular}{lccccc}
\hline Local & Hospedeiro & Posturas & N $^{\text {o de ovos }}$ & Parasitismo (\%) & Parasitóide \\
\hline ÁREA 1 & E. heros & 276 & 1271 & 84,7 & T. podisi $(98 \%)$ \\
& & & Neorileya sp. (1\%)
\end{tabular}

ÁREA 5

ÁREA 6

ÁREA 7
E. heros

P. guildinii
E. heros
E. heros
E. heros

\section{9}

170

72

407

P. guildinii

79

244

ÁREA 8

959

415

859

374

1747

1535
T. basalis (1\%)

T. podisi (100\%)

T. podisi (100\%)

T. podisi (100\%)

T. podisi (95\%)

Neorileya sp $(1,5 \%)$

T. basalis $(3,5 \%)$

T. podisi $(92 \%)$

Neorileya sp. $(2,4 \%)$

T. basalis $(5,6 \%)$

T. podisi $(98 \%)$

Neorileya sp. $(0,7 \%)$

T. basalis $(0,7 \%)$

Ooencyrtus sp. $(0,6 \%)$

T. podisi $(100 \%)$

T. podisi (100\%)

T. podisi (100\%)

T. podisi (100\%)

T. podisi $(98 \%)$

Neorileya sp. $(0,5 \%)$

T. basalis $(1,2 \%)$

Ooencyrtus sp. $(0,3 \%)$

T. podisi $(97,1 \%)$

Neorileya sp. $(0,9 \%)$

T. basalis $(2,0 \%)$

Ciência Rural, v.35, n.2, mar-abr, 2005. 
tóides, tanto para o controle da lagarta da soja, quanto para os percevejos fitófagos, fato que não ocorreu nas outras duas áreas.

Do mesmo modo, que ocorreu em 2001, o microhimenóptero $\boldsymbol{T}$. podisi foi a espécie predominante, em ovos de $\boldsymbol{E}$. heros $(98 \%)$ e $\boldsymbol{P}$. guildinii $(97,1 \%)$. Em porcentagens menores, foram obtidas as espécies T. basalis e Ooencyrtus sp. (Chalcidoidea: Encyrtidae) (Tabela 3), à semelhança dos resultados obtidos por GODOY \& ÁVILA (2000) em levantamentos de parasitóides de ovos de percevejos realizados na região de Dourados, MS.

Conclui-se que, na região de São Gabriel do Oeste, MS, as posturas de $\boldsymbol{E}$. heros apresentam, em média, cerca de $61 \%$ de parasitismo nos ovos, enquanto em $\boldsymbol{P}$. guildinii a ocorrência é de cerca de $32 \%$. T. podisi é a principal espécie de parasitóide que ocorre em ovos de $\boldsymbol{E}$. heros e $\boldsymbol{P}$. guildinii na região.

\section{AGRADECIMENTOS}

À Fundação de Amparo à Pesquisa do Estado de São Paulo (FAPESP), pela concessão da bolsa de doutorado ao primeiro autor e auxílio de reserva técnica. À Secretaria de Meio Ambiente (SEMA) do Estado de Mato Grosso do Sul, por ceder o laboratório em São Gabriel do Oeste, MS. À Dra. Beatriz S. Corrêa-Ferreira, da Embrapa-Soja, Londrina, PR e a Dra. Marta S. Loiácono, do Museo de La Plata, Buenos
Aires, Argentina, pela identificação das espécies de parasitóides.

\section{REFERÊNCIAS BIBLIOGRÁFICAS}

CORRÊA-FERREIRA, B.S. Ocorrência, no Brasil, de Trissolcus basalis, parasita de ovos de Nezara viridula. Pesquisa Agropecuária Brasileira, v.15, p.127-128, 1980.

CORRÊA-FERREIRA, B.S. Utilização do parasitóide de ovos Trissolcus basalis (Wollaston) no controle de percevejos da soja. Londrina : Embrapa-CNPSo, 1993. 30p. (Circular Técnica 11).

EMBRAPA. 2000. Recomendação técnica para a cultura da soja na região Central do Brasil 1999/2000. Londrina: Embrapa-CNPSo, 2000. 266p. (Documentos 132).

GODOY, K.B.; ÁVILA, C.J. Parasitismo natural em ovos de dois percevejos da soja, na região de Dourados, MS. Revista de Agricultura, v.75, p.271-279, 2000.

JONES JUNIOR, W.A. The distribution and ecology of pentatomid pests of soybeans in South Carolina. 1979. $150 \mathrm{f}$.

MOREIRA, R.P.; BECKER, M. Mortalidade, no período de préemergência, de parasitóides de Nezara viridula (L., 1758) (Hemiptera: Pentatomidae), no estágio de ovo na cultura da soja. Anais Sociedade Entomológica do Brasil, v.16, p.297-313, 1987.

PANIZZI, A.R.; SLANSKY JR, F. Review of Phytophagous pentatomids (Hemiptera: Pentatomidae) associated with soybean in Americas. Florida Entomologist, v.68, p.184-214, 1985.

YEARGAN, K.V. Parasitism and predation of stink bug eggs in soybean and alfafa field. Environmental Entomology, v.8, p.15$719,1979$. 